\title{
Dermal in vitro penetration of methiocarb, paclobutrazol, and pirimicarb
}

\author{
Jesper B Nielsen, Flemming Nielsen
}

\begin{abstract}
Objectives-The dominant route of occupational exposure to pesticides in horticulture is dermal. However, preventive measures are seldom used when handling plant cultures recently treated with pesticides, thus causing significant dermal exposure and potential absorption. Assessment of exposure often depends on biological monitoring of blood or urine samples. The skin often acts as a temporary reservoir for chemicals before absorption. Failure to consider the lag time between dermal exposure and appearance of pesticide or metabolites in the general circulation may lead to false conclusions about assessment of exposure.

Methods-In an experimental model in which in vitro static diffusion cells were mounted with human skin, dermal penetration of three extensively used pesticides (methiocarb, paclobutrazol, pirimicarb) was evaluated.

Results-Pirimicarb and paclobutrazol had comparable rates of dermal penetration and lag times of around 18 hours. Methiocarb had a considerably shorter lag time. Dermal penetration continued for extended periods after exposure had ended.

Conclusions-With lag times sometimes considerably longer than a normal working day, biological monitoring at the end of exposure may seriously underestimate the actual exposure. There may be implications for regulatory guidelines, which often require only 24 hour observation periods.

(Occup Environ Med 2000;57:734-737)
\end{abstract}

Keywords: dermal penetration; pesticides; in vitro

The dominant route of occupational exposure to pesticides in horticulture is dermal. Thus, a recent study showed that the greatest deposition of pirimicarb occurred on the hands and arms, and that this represented $62 \%$ of the total dose, whereas no detectable air residue samples of pirimicarb were found while workers were debudding plants. ${ }^{1}$ Therefore, estimates of dermal absorption have become a critical part of risk assessment for human occupational exposure to pesticides, and the measurement of percutaneous absorption of pesticides is required as part of the registration and hazard assessment process.

Some of the most extensively used pesticides in horticulture are fungicides and growth retardants. These pesticides are often used repeatedly during long periods on large areas of greenhouse cultures, and plants are often handled within very short periods after being treated. Preventive measures - such as glovesare seldom used when handling plant cultures recently treated with fungicides or growth retardants, thus causing significant dermal exposure and potential absorption.

Assessment of exposure may rely on video imaging $^{2}$ or biological monitoring through measurement of pesticides or their metabolites in blood or urine..$^{2-5}$ Some chemicals will, however, remain in the stratum corneum for some time before being absorbed into the general circulation. Therefore, the validity of biological monitoring will depend on knowledge of the relation between time of exposure and time for blood or urine sampling - that is, knowledge of the lag time between dermal exposure and appearance of pesticide or metabolite in the general circulation. ${ }^{56}$ Failure to consider this factor may cause false conclusions about assessment of exposure.

With an in vitro experimental model with human abdominal skin, ${ }^{78}$ we studied the percutaneous penetration of two fungicides (pirimicarb and methiocarb) and a growth retardant (paclobutrazol). The three pesticides were selected on the basis of quantities applied in Danish horticulture and to represent different characteristics of solubility. Thus, the solubility in water varied from $0.027 \mathrm{~g} / \mathrm{l}$ (methiocarb and paclobutrazol) to $2.7 \mathrm{~g} / 1$ (pirimicarb) and the corresponding logarithm of the octanol-water partition coefficient $\left(\log \mathrm{P}_{\text {ow }}\right)$ values from 3.3 to 1.7 , respectively. The pesticide concentrations were chosen to represent expected and legal concentrations in the working environment.

\section{Materials and methods}

CHEMICALS

Pirimicarb (2-dimethylamino-5,6-dimethylpyrimidin-4-yl dimethylcarbamate; CAS No 23103-98-2; molecular weight $238 \mathrm{~g} / \mathrm{mol}$ ), and methiocarb (4-methylthio-3,5-xylyl methylcarbamate; CAS No 2032-65-7; molecular weight $225 \mathrm{~g} / \mathrm{mol}$ ) were obtained as reference materials (Ehrenstorfer, Germany). Paclobutrazol ((2RS,3RS)-1-(4-chlorophenyl)-4,4dimethyl-2-(1H-1,2,4-triazol-1-yl) pentan-3ol; CAS No 76738-62-0; molecular weight $294 \mathrm{~g} / \mathrm{mol}$ ) was obtained as reference material (Institute of Organic Industrial Chemistry, Poland). Phosphate buffer $\left(\mathrm{Na}_{2} \mathrm{HPO}_{4}, 2 \mathrm{H}_{2} \mathrm{O}\right.$; Merck, Germany) was used in the receptor chamber before experiments $(0.05 \mathrm{M} ; \mathrm{pH}=7.4)$ and water was purified with a Milli-Q system from Millipore (MA, USA). An acetonitril and 
methanol mixture "Lichrosolv" (BDH, Poole, England) was used for high performance liquid chromatography (HPLC) analysis.

\section{SKIN MEMBRANES}

Human cadaver abdominal skin was obtained from white women without skin disease and a median (range) age of 71 (36-95) years. Samples were stored at $-20^{\circ} \mathrm{C}$ for a period not exceeding 1 month and allowed to thaw at room temperature before use. The skin was cleaned, and subcutaneous fat removed before mounting in the static diffusion cells. It should be noted that the use of full thickness skin in the static cell model may slightly overestimate in vivo lag times as the system will not maintain perfusion.

EXPERIMENTAL MODEL

As previously described, ${ }^{89}$ in vitro static diffusion cells adapted from Southwell et $a l^{10}$ were mounted with the skin on a metal grid and placed on a water bath $\left(32^{\circ} \mathrm{C}\right)$ with individual magnetic stirring. The median diffusion area was $2.04 \mathrm{~cm}^{2} /$ cell. Before application of the pesticide, the epidermal site was exposed to ambient laboratory conditions and the dermis bathed in phosphate buffer for 18 hours. Further, the barrier integrity was evaluated by capacitance measurements (Lutron DM-9023, Acer AB, Sweden), and cells with a capacitance above $55 \mathrm{nF}$ were excluded. During experiments the phosphate buffer was exchanged, and a $50 \%$ water:ethanol solution was used in receptor and donor chambers. Median number of diffusion cells per group was nine and the pesticides were applied to the donor chamber in a total volume of $600 \mu \mathrm{l}$. During the experimental periods, donor and receptor chambers were covered with parafilm to avoid evaporation. Samples were taken from the receptor chamber at appropriate intervals and replaced with fresh receptor fluid, keeping an infinite sink. In experiments with time limited exposure, pesticide solutions were removed from the donor chamber at 4.5 hours or 24 hours and the donor chamber was washed immediately three times with phosphate buffer to remove pesticide remaining on the surface of the skin membranes.

\section{PESTICIDE ANALYSIS}

Pesticide concentrations were measured in the receptor medium by HPLC. Briefly, $50 \mu \mathrm{l}$ receptor medium was injected into a $\mathrm{Li}_{-}$ Chrospher RP-18, 125-4 column by means of a Kontron 360 autosampler. Pirimicarb was eluted with a mobile phase consisting of methanol:water (70:30), whereas paclobutrazol and methiocarb were eluted with acetonitrile:water (50:50). A flow rate of $1 \mathrm{ml} / \mathrm{min}$ provided by a Kontron HPLC 420 pump was used for both eluents. Detection was performed by a Kontron 430 UV-detector. Measurement was based on the peak area of the compound related to a standard curve. All data calculations were performed by a personal computer (Victor, Sweden) with Kontron MT-450 software.

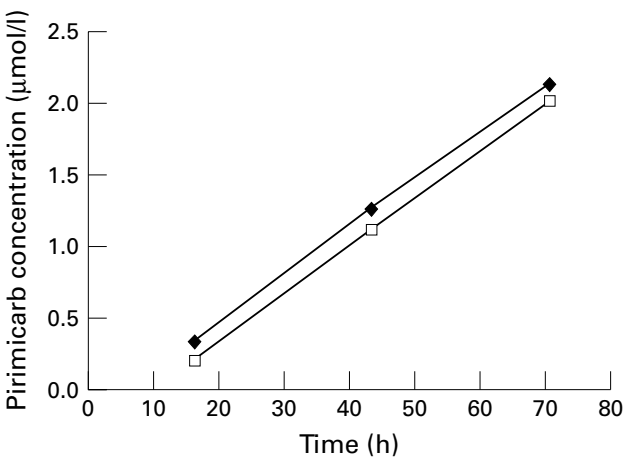

Figure 1 Percutaneous penetration of pirimicarb $(0.2$ $m M)$ during 72 hours continuous exposure in two independent experiments ( $n=18$ cells/experiment). Results are given as mean concentrations of pirimicarb in the receptor chamber

\section{DATA PROCESSING}

Data on percutaneous penetration are presented as means of the concentrations of pesticides $(\mathrm{mM})$ in the receptor chamber. As a dilution factor was introduced every time a sample was removed from the receptor chamber and replaced by pure receptor, all data were corrected for this dilution.

ETHICS

The study was approved by the regional ethics review committee.

\section{Results}

In experiment 1 variations within donors, between donors, and between experiments were evaluated. The coefficient of variation (CV) for variation within donors - that is, the variation between cells mounted with the same donor-was $18 \%-55 \%$ (data not shown). The $\mathrm{CV}$ between donors - that is, the variation between donors in the same experiment-was $40 \%-67 \%$ (data not shown), and was thus slightly larger than the variation within donors. The variation between two parallel experiments with pirimicarb, each with three different donors and 18 cells, was only $3 \%$ for the rate of percutaneous penetration (fig 1). Furthermore, a clear proportionality between time and amount of penetrated pirimicarb was found, and the lag time for percutaneous penetration of pirimicarb was estimated to be 15-18 hours (fig 1 ).

The percutaneous penetrations of pirimicarb and paclobutrazol administered at $0.2 \mathrm{mM}$ in the donor chamber were comparable for penetration rates and total amounts of pesticide penetration during the initial 48 hours (fig 2). Between 48 hours and 72 hours, significantly more paclobutrazol than pirimicarb passed the skin barrier (fig 2). Reducing the initial concentration of paclobutrazol in the donor phase from $0.2 \mathrm{mM}$ to $0.1 \mathrm{mM}$ caused a parallel decline in the amount of paclobutrazol penetrating the skin, but the apparent lag time was unaffected (fig 2). The initial penetration rate of methiocarb was considerably faster and the amount of methiocarb transferred to the receptor chamber was also significantly higher than the other two pesticides applied at a concentration of $0.2 \mathrm{mM}$ (fig 2). Based on the total 


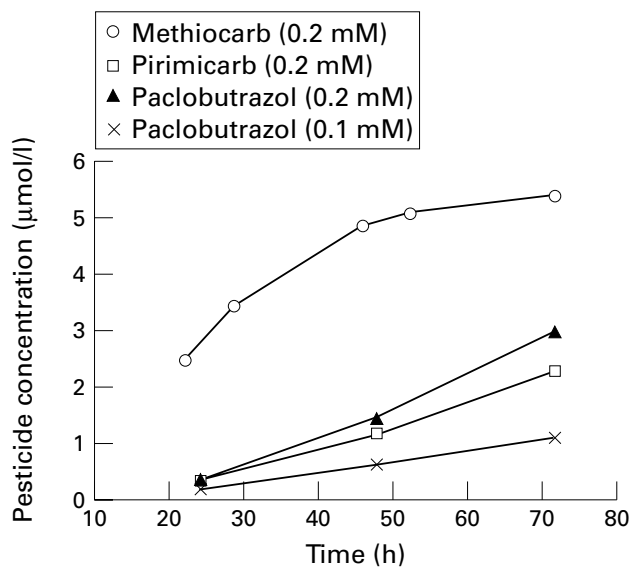

Figure 2 Percutaneous penetration of methiocarb (0.2 $\mathrm{mM})$, pirimicarb $(0.2 \mathrm{mM})$, and paclobutrazol $(0.1 \mathrm{mM}$ and $0.2 \mathrm{mM})$ during 72 hours continuous exposure $(n=9$ cells per data point for methiocarb and paclobutrazol, $n=36$ cells per data point for pirimicarb). Results are given as mean concentrations of pesticides in the receptor chamber.

amount of pesticide added to the donor chamber and knowledge of the volumes in the donor and receptor chambers, equilibrium between the two chambers would be expected at a concentration close to $6 \mu \mathrm{mol} / \mathrm{l}$. For methiocarb, this limit was approached after about 48 hours, as indicated by the sharp decline in penetration rate (fig 2). An apparent lag time of 18 hours for percutaneous penetration could be estimated for pirimicarb as well as for paclobutrazol. For methiocarb, the estimated lag time was considerably shorter but more uncertain (fig 2).

Reducing the exposure time for paclobutrazol and methiocarb to 4.5 hours and 24 hours, respectively, reduced the amount of pesticide penetrating the skin during the 72 hour observation period compared with the continuous exposure situation (figs 3 and 4). The penetration rates for paclobutrazol were significantly slower than for methiocarb. There was a slow but constant penetration of pesticides to the receptor chamber that continued even after the pesticides were removed form the donor chamber (figs 3 and 4). Up to 10 hours after exposure was initiated, paclobutrazol could still not be found in the receptor phase. After 24 hours, paclobutrazol could be measured in the receptor phase from the two groups which had been exposed for 24 hours, whereas penetration of paclobutrazol in the group exposed for 4.5 hours was found after 48 hours. Thus, the lag time for percutaneous penetration of paclobutrazol was between 10 and 24 hours and, based on extrapolations from the two groups exposed for the longest time, close to 20 hours (fig 3). Based on extrapolation methiocarb had a lag time for penetration that was closer to 10 hours, and methiocarb could be measured in all three groups at 24 hours (fig 4). Thus, in both groups exposed for 4.5 hours only, neither methiocarb nor paclobutrazol could be measured in the receptor phase at the end of exposure, but both appeared with considerable delay (figs 3 and 4). Also in the groups exposed for 24 hours, both paclobutrazol and methiocarb continued to accumulate in

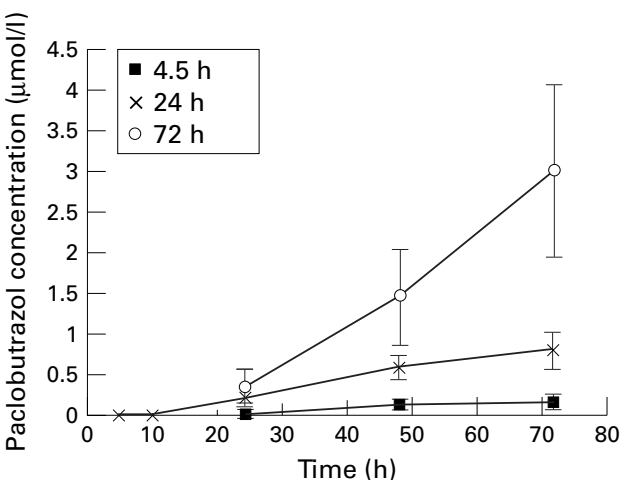

Figure 3 Percutaneous penetration of paclobutrazol (0.2 $m M$ ) observed up to 72 hours after different durations of exposure ( $n=5-9$ cells per data point). Results are given as mean (SD) concentrations of paclobutrazol in the receptor chamber.

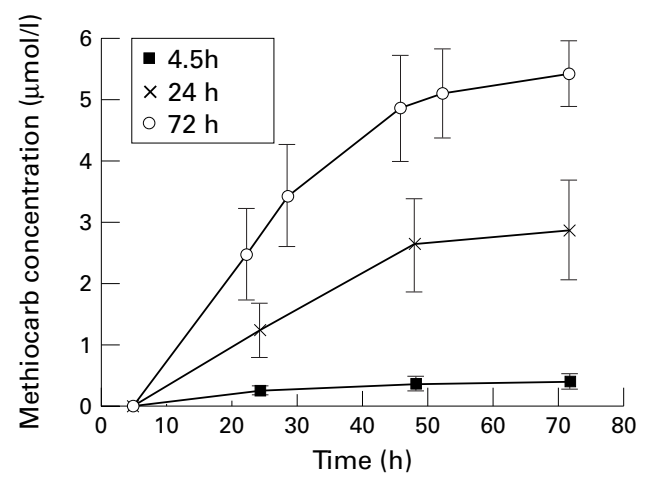

Figure 4 Percutaneous penetration of methiocarb (0.2 $m M)$ found up to 72 hours after different durations of exposure ( $n=5-9$ cells per data point). Results are given as mean (SD) concentrations of methiocarb in the receptor chamber.

the receptor phase long after the pesticides were removed from the donor phase (figs 3 and $4)$.

\section{Discussion}

The validity of an experimental model depends on knowledge of experimental variation. Data on variations within and between donors in in vitro studies are seldom reported and results are often given as mean values of observations from 3-5 diffusion cells. These studies often report CVs ranging from $30 \%$ to $70 \% .^{3}$ This variation is comparable with the variations within and between donors reported in the present study. The slightly larger variation between than within donors suggests an experimental design in which individual donors are represented in experimental groups as well as controls. These variations are, however, more or less inherent to the experimental model due to the heterogeneity of the donors. Thus, the precision could be increased by increasing the number of cells per group. As evident from figure 1, this will generate highly reproducible results in penetration rate as well as lag time. An increased level of repeatability of penetration rates would also be expected if the number of point estimates of penetration during the experimental period were increased. ${ }^{8}$

The comparable penetration characteristics of pirimicarb and paclobutrazol and the differ- 
ences found in penetration rate, amount, and lag time between paclobutrazol and methiocarb indicate that factors other than water solubility or $\log \mathrm{P}_{\text {ow }}$ affect the percutaneous penetration of these compounds. Thus, despite identical solubility characteristics and comparable molecular weights, methiocarb had a considerably shorter lag time for percutaneous penetration than paclobutrazol. This may have important bearings in the approach to assessment of exposure and risk in which the relation between structure and activity is considered.

Despite variations, the lag times were in all cases between 10 and 18 hours and as shown for paclobutrazol were not dependent on concentration in the donor phase. The mean lag time for methylparathion has previously been estimated to vary between 3 and 7 hours depending on formulation. ${ }^{6}$ With lag times sometimes considerably longer than a normal working day, it becomes increasingly important to study to what extent absorption (the amount of pesticide measurable in the receptor phase) will increase after exposure has stopped. The initial experiments used continuous exposure for 72 hours.

The occupational exposure situation is different. We therefore refined our study design with exposure times of 4.5 and 24 hours besides the usual 72 hours. As already found in the first experiment, paclobutrazol did not penetrate the skin very readily. The second experiment with paclobutrazol showed that after 4.5 hours of exposure, it could take between 24 and 48 hours before paclobutrazol could be measured in the receptor phase. Even methiocarb, which penetrates the skin much more rapidly than paclobutrazol, did not appear in the receptor fluid within 10 hours of the start of exposure. Furthermore, in all experiments the concentration in the receptor fluid continued to increase long after exposure had been stopped by removing the pesticides from the donor chamber.
These findings are of crucial importance in cases of biological monitoring where a blood sample at the end of exposure may seriously underestimate the actual exposure and in some cases even indicate the total absence of exposure or absorption. Further, implications may also be relevant to the United States Environmental Protection Agency guidelines for dermal absorption studies, which require a 24 hour observation period only. ${ }^{11}$

Jan Beyer, Vibeke Kvist, and Birgit Larsen are acknowledged for excellent technical assistance. The project was supported by a grant from the Danish Occupational Health Foundation

1 Archibald BA, Solomon KR, Stephenson GR. Estimating pirimicarb exposure to greenhouse workers using video imaging. Arch Environ Contam Toxicol 1994;27:126-9.

2 Archibald BA, Solomon KR, Stephenson GR. Estimation of pesticide exposure to greenhouse applicators using video imaging and other assessment techniques. Am Ind Hyg Assoc f 1995;56:226-35.

3 Scott RC, Batten PL, Clowes HM, et al. Further validation of an in vitro method to reduce the need for in vivo studies for measuring the absorption of chemicals through rat skin. Fundam Appl Toxicol 1992;19:484-92.

4 Meuling WJ, Franssen AC, Brouwer DH, et al. The influence of skin moisture on the dermal absorption of propoxur in human volunteers: a consideration for biological poxur in human volunteers: a consideration for biological

5 Thongsinthusak T, Ross JH, Saiz SG, et al. Estimation of dermal absorption using the exponential saturation model. Regul Toxicol Pharmacol 1999;29:37-43.

6 Sartorelli P, Aprea C, Bussani R, et al. In vitro percutaneous penetration of methyl-parathion from a commercial formulation through the human skin. Occup Environ Med 1997;54:524-5.

7 Frankild S, Andersen KE, Nielsen GD. Effect of sodium lauryl sulfate (SLS) on in vitro percutaneous penetration of water, hydrocortisone and nickel. Contact dermatitis 1995; 32:338-45.

8 Nielsen J. Influence of four detergents on in vitro barrier function of human skin. Int f Occup Environ Health 2000;6: $143-7$.

9 Nielsen GD, Nielsen JB, Andersen KE, et al. Effect of industrial detergents on the barrier function of human skin. Int $\mathcal{F}$ Occup Environ Health 2000;6:138-42.

10 Southwell D, Barry BW, Woodford R. Variations in permeability of human skin within and between species. Int $\mathcal{F}$ Pharm 1994;18:299-309.

11 Farber T, Zendzian R. Pesticide registration in the United States. In: Scott RC, Hadgraft J, Guy RH, eds. Prediction of percutaneous penetration: methods, measurements, modelling. percutaneous penetration: methods, measure 